\title{
New Persistent Opioid Abuse and the Brain Reward Circuit
}

\author{
Ly Zhang*, Philip G. Boysen \\ Department of Anesthesiology, University of Mississippi Medical Center, \\ The Mississippi Critical Care Organization, USA
}

Article Info

\section{Article Notes}

Received: December 06, 2019

Accepted: April 08, 2020

\section{*Correspondence:}

*Dr. Ly Zhang, Department of Anesthesiology, University of Mississippi Medical Center, The Mississippi Critical Care Organization, USA; Email: lyzhang12@gmail.com.

${ }^{\circ} 2020$ Zhang L. This article is distributed under the terms of the Creative Commons Attribution 4.0 International License.
New persistent opioid abuse in peri-operative and periprocedural patients is reported to be $\sim 6 \%$ in two large populationbased studies ${ }^{1}$. In addressing the opioid crisis the CDC has developed three categories. The first is prescription drugs, when legal and approved opioids are prescribed by licensed professionals ${ }^{2}$. The second and third categories involve illicit drugs, specifically heroin and fentanyl ${ }^{3,4}$. Over time CDC data indicates a sharp uptick in opioid deaths for heroin and fentanyl, but a flat incidence of overdose with prescription drugs ${ }^{5}$. Understanding the neurobiology of addiction adds insight to the problem and treatment. In addition, the social and public health issues are integral to the understanding of how the brain reward circuit is activated in the first place.

The brain reward circuit was described in rodents, then in nonhuman primates 50 years ago. Rats taught to push a lever to self administer addictive drugs (heroin, cocaine amphetamines) would not eat or sleep, began excessive lever-pushing, and exhibited other aspects of addictive behavior. When the environment is subsequently withdrawn, the pleasure is not forgotten, but remains intact for months and can be activated in response to addiction cues or stress ${ }^{6}$.

In effect, the reward circuit is commandeered by the drug. The key to this physiology is in the brain mesolimbic system located in the ventral tegmental area (VTA) in the base of the brain ${ }^{7}$. The VTA targets the nucleus accumbens (NA) by sending dopamine from its terminal to the NA. When the dopamine pathway is ablated, experimental animals show no interest in substances of abuse ${ }^{8}$.

Neurotransmitters activate the amygdala to assess whether the experience is pleasurable or aversive, and whether it should be repeated or avoided, thus forging the connection between the experience itself and other cues to that experience ${ }^{9}$. The hippocampus records the memory of the experience ${ }^{10}$. The frontal cortex processes information to determine ultimate behavior ${ }^{11}$.

Over the past 15 years, MRI and PET scans have confirmed the existence of the brain reward circuit in humans, including responses to triggers and cues. Diverse drugs can activate the brain reward circuitry to release DA from the axon into synaptic clefts; reuptake and repackaging of the DA back into the VTA follows. Cocaine disables the transporter protein that returns the DA to the VTA, resulting in a "DA flood" at the terminals. Opioids bind directly to neurons in the VTA and have a direct effect on cellular function ${ }^{12}$.

Addiction progresses from tolerance to escalation of drug use, then dependence, and finally the painful and emotional reactions characteristic of withdrawal if the drug is cut off or discontinued. 
Within the NA are cell transcription factors, and other neurotransmitters, responsible for the final common pathway to addiction. Cyclic AMP Response Element Binding protein (CREB) regulates gene expression to actively produce dynorphin, a natural molecule with opioid like effects Dynorphin inhibits neurons in the VTA, suppressing the reward circuit which results in tolerance. The elaboration of CREB and its effects lasts only a matter of days ${ }^{13}$.

Another transcription factor, delta FosB gradually rises to a peak level which will last for months. The rise in this transcription factor is accompanied by microscopic anatomic changes. Dendrites elaborate spiny projections resulting in a bushy appearance that parallels the intransigence of addiction. Glutamate is the major neurotransmitter for the amygdala, hippocampus, frontal cortex, and the VTA ${ }^{14}$.

There are some individuals with a genetic predisposition to addiction ${ }^{15,16}$. For a perioperative patient, it can take only a few instances of exposure to a drug (or even only one) for an addictive drug to "hi-jack" the brain reward circuitry. This can occur with prescriptive or recreational drugs, including alcohol and nicotine, and overeating and compulsive gambling. Thus, understanding the brain reward circuitry corroborates addiction as a disease with definitive alterations in neurobiology. It also explains the craving and recidivism that is part of addictive behavior. It points the way to future research to provide specific therapy to treat addiction. Finally, it establishes the need to examine clinical practices.

In September 2001, Goldstein published Addiction: From Biology to Public Policy ${ }^{17}$. He describes addiction as a brain disease, and also provides factual information about addiction as "a much neglected societal problem". This position is corroborated by the aforementioned CDC report, previously alluded to, Opioid Overdose: Understanding the Epidemic, indicating that regulation and public policy resulted in no death increases due to commonly prescribed opioids starting from 2010, whereas the illicit use of heroin and synthetic fentanyl caused a marked increase in overdose deaths. (Figure) ${ }^{5}$, Published data include ${ }^{18}$ :

- From 1999 to 2017, more than 700,000 people died from drug overdose.

- In 2017, there were 70,200 overdose deaths, $68 \%$ involving an opioid.

- In 2017, the number of deaths involving opioids (including prescription opioids and illegal opioids like heroin and illicitly manufactured fentanyl) was 6 times higher than 1999.

The WONDER study (wide-ranging online data for epidemiologic research), part of the CDC and published by the National Center for Health Statistics, reported that in the same year, 2017, an average of 130 Americans died every day from an opioid overdose ${ }^{19}$.

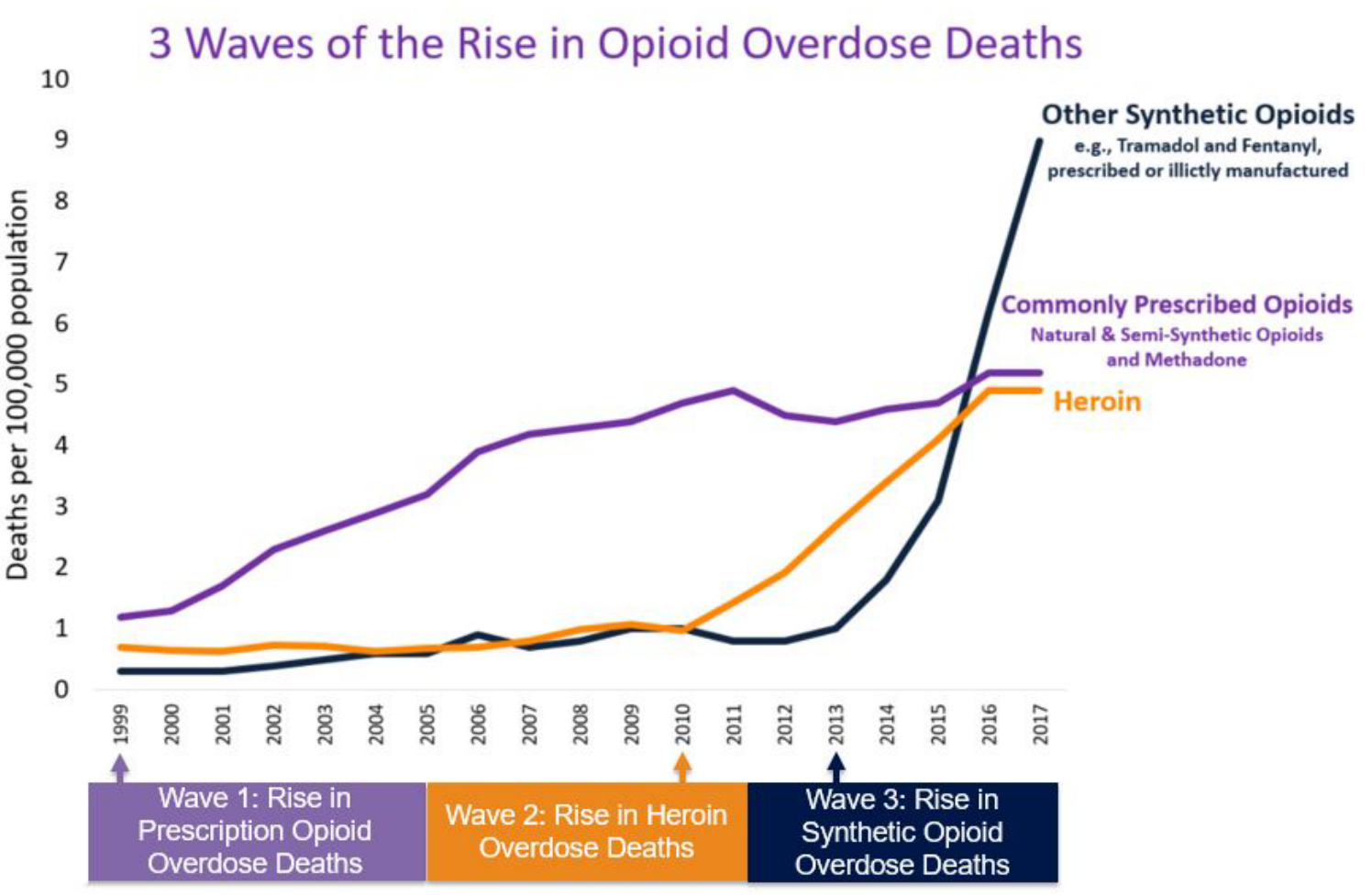

SOURCE: National Vital Statistics System Mortality File.

Figure: https://www.cdc.gov/drugoverdose/epidemic/index.html 
The CDC report identified three waves of opioid deaths:

WAVE 1: During the 1990 - 2010 time frame a rise in prescribed opioids, both natural and semi-synthetic opioids and methadone was noted ${ }^{20}$.

WAVE 2: The second wave began in 2010, with a rapid increase in overdose deaths involving heroin. Starting in 2010 there was no increase in the incidence of death from commonly prescribed opioids.

WAVE 3: The third wave began in 2013, with a significant increase in overdose deaths due to synthetic opioids, particularly involving illicitly manufactured fentanyl, and of further concern a combination of fentanyl with heroin, cocaine, and other counterfeit medications, usually unknown to purchasing addicts ${ }^{21}$.

While the biology of addiction provides insight into a complex problem, addiction to opioids is a social and public health problem ${ }^{22}$. A recent report noted geographic variation in opioid prescribing in the United States, raising questions about opioid prescribing practices, and warned of the possibility of under-treatment of patients with legitimate need to manage pain, versus the overprescribing noted in their study ${ }^{23}$. In the effort to manage appropriate prescribing there are legal issues that will impact the prescribing physician ${ }^{24}$. Monitoring pain in clinical practice is difficult, and there is concern about using patient satisfaction as a proxy for quality care ${ }^{25}$. Multidisciplinary and multi-professional engagement will be required of providers, hospitals, the pharmaceutical industry, and federal and state government agencies.

\section{References}

1. Brummett CM, Waljee JF, Goesling J, et al. New persistent opioid abuse after minor and major surgical procedures in US adults. JAMA Surg. 2017; 152: 152-155.

2. https://www.cdc.gov/drugoverdose/opioids/prescribed.html

3. https://www.cdc.gov/drugoverdose/opioids/heroin.html

4. https://www.cdc.gov/drugoverdose/opioids/fentanyl.html

5. https://www.cdc.gov/drugoverdose/epidemic/index.html

6. Nestler EJ. Molecular basis of long term plasticity and underlying addiction. Nat Rev Neurosci. 2001; 2: 119-128.

7. Pierce RC, Kumaresan V. The mesolimbic dopamine system: the final common pathway or the reinforcing effects of drug abuse? Neurosci Biobehav Rev. 2006; 30: 215-238.

8. Trezza V, Damstegt R, Achterberg EJ, et al. Nucleus accumbens mu opioid receptors mediate social reward. J Neurosci. 2011; 17: 63626370.

9. Jackson ME, Moghaddam B. Amygdala regulation of nucleus accumbens dopamine output is governed by prefrontal cortex. J Neurosci. 2001; 21: 676-681.

10. Belujon P, Grace AA. Hippocampus, amygdala and stress: interacting systems that affect susceptibility to addiction. Ann N Y Acad Sci. 2011; 1216: $114-121$.

11. Tzschentke TM. The medial prefrontal cortex as a part of the brain reward system. Amino Acids. 2000; 19: 211-219.

12. Nestler EJ. The neurobiology of cocaine addiction. Sci Pract Perspect. 2005; 3: 4-10.

13. Walters CL, Kuo YC, Blendy JA. Differential distribution of CREB in the mesolimbic dopamine reward pathway. J Neurochem. 2003; 87: 12371244.

14. Nestler EJ, Barrot M, Self DW. Delta FosB: A sustained molecular switch for addiction. Proc Nat Acad Sci. 2001; 98: 11042-11046.

15. Nestler EJ. Genes and addiction. Nature Genetics. 2000; 26: 277-281.

16. Bevilacqua L, Goldman D. Genes and addictions. Clin Pharmacol Ther. 2009; 85: 359-361.

17. Goldstein A. Addiction: from Biology to Drug Policy. 2 nd edition 2001 Oxford University Press.

18. https://www.cdc.gov/injury/features/prescription-drug-overdose/ index.html

19. https://www.drugabuse.gov/related-topics/trends-statistics/ overdose-death-rates

20. Scholl L, Seth P, Karlisa M, et al. Drug and opioid involved opioid deaths - United States, 2013-2017. MMWR. 2018; 67: 1419-1427.

21. Rudd RA, Aleshire N, Zibbell JE, et al. Increases in drug and opioid overdose deaths - United States 2000 - 2014, MMWR. 2016; 64: 1378-1382.

22. Kolodny A, Courtwright DT, Hwang CC, et al. The prescription opioid and heroin crisis: a public health approach to an epidemic of addiction. Ann Rev Public Health. 2015; 36: 559-574.

23. McDonald DC, Carlson AB, Izrael D. Geographic variation in opioid prescribing in the USJ Pain. 2012; 13: 988-996.

24. Dineen KK, DuBois HM. Between a rock and a hard place: can physicians prescribe opioids to treat pain adequately while avoiding legal sanction? Am J Law Med. 2016; 42: 7-52.

25. Rummans TA, Burton CB, Dawson NL. How good intentions contributed to bad outcomes: the opioid crisis. May Clin Proc. 2018; 93: $344-350$ 